\title{
PROMOTING AUTOMOBILE SAFETY BELT USE BY YOUNG CHILDREN
}

\author{
Karen M. Sowers-Hoag, Bruce A. Thyer, and Jon S. Bailey \\ FLORIDA STATE UNIVERSITY
}

\begin{abstract}
A program using behavioral practice, assertiveness training, and social and contrived reinforcers was developed to establish and maintain automobile safety belt use by young children. Sixteen children (ages 4.8 to 7 years) who never used their safety belts during a 5 -day preexperimental observation period were randomly assigned to two groups of eight each. A multiple baseline design across groups was used to evaluate the effectiveness of the training program. During the 8-day baseline period for Group 1, no children used their safety belts when unobtrusively observed while being driven from school. During the 26-day intervention period, the children were buckled up on $96 \%$ of the observations. Follow-up probes conducted 2-3 months after program discontinuance found safety belt use to range from $86 \%$ to $100 \%$. For Group 2, the 14-day baseline safety belt use averaged $6 \%$ and increased to a mean of $81 \%$ during the 20 -day training and maintenance program. Followup probes 2-3 months later found safety belt use to occur during $75 \%$ to $96 \%$ of the observations. Parent questionnaires indicated the generalizability and social validity of the program.

DESCRIPTORS: safety, prevention, social work, safety belts
\end{abstract}

Automobile accidents are the leading cause of death and injury for American children, ranking ahead of all other types of accidents or childhood diseases. Each year, children aged 14 years and under suffer over 1,500 fatalities and more than 125,000 injuries as a result of vehicle collisions and sudden stops (National Safety Council, 1983). There is unequivocal evidence that safety belts and child safety seats, if consistently used, can prevent more than half of all deaths and injuries of motor vehicle occupants (Highway Safety Research Center, 1976).

Large-scale efforts intended to encourage safety belt use have included engineering approaches, public education, and mandatory safety belt and

This research was submitted by the first author to the School of Social Work, Florida State University, in partial fulfillment of the requirements for a Doctor of Philosophy degree. Karen Sowers-Hoag is now at the School of Social Work, Florida International University.

Copies of the training manual, individual subject data, and the validation questionnaire are available from the second author, and in Sowers-Hoag (1986).

The authors gratefully acknowledge the cooperation of Headmistress Mooney and the staff of the Holy Comforter Day School, and the dedicated efforts of the observers, including Brenda Ayala, Carol Barr-Johnson, Meg Corning, Kathie Johnson, Laurie Kehlenbeck, Linda McNeil, and Chris Osinski.

Reprints may be obtained from Bruce A. Thyer, School of Social Work, Florida State University, Tallahassee, Florida 32306. child safety seat use laws (Geller, Casali, \& Johnson, 1980). Educational programs such as television and radio advertisements, billboard prompts, films, and pamphlets have typically produced unimpressive results (Geller et al., 1980).

Most research on safety belt promotion has focused on adult use (for a comprehensive review see Streff \& Geller, 1986). Typical intervention programs have involved various behavioral strategies, including reminder flyers placed on automobile windshields; community, university, or industrialbased programs providing contrived reinforcers contingent upon observed or pledged safety belt use; publicly posted feedback of organizational safety belt use percentages; safety belt lotteries; dashboard reminder stickers; and "Flash-for-Life" cards used as prompts for unbuckled drivers (Geller, Bruff, \& Nimmer, 1985; Thyer \& Geller, in press; Thyer, Geller, Williams, \& Purcell, in press). These behavioral programs often produce modest but practical increases in safety belt use which may be partially maintained after the programs are discontinued.

Research on the promotion of child safety devices has taken two main directions: encouraging parents to restrain infants and small children in safety seats or belts, as appropriate, and in directly helping older children to acquire and maintain safety belt use behaviors. An extensive body of research exists in 
the psychological and pediatric literatures, recently reviewed by Roberts and Turner (1984), on the various strategies intended to increase correct parental use of child safety seats. Although mandatory use laws for safety seats have been enacted in all 50 states, observed compliance typically ranges between $10 \%$ and $30 \%$ (Roberts \& Turner, 1986), suggesting the need for developing effective techniques to increase the consistent and proper use of child safety seats.

Little research has been conducted on increasing the safety belt use of children. Roberts and Fanurik (1986) conducted an A-B-A analysis of a schoolbased lottery program designed to promote safety belt use by elementary school children attending two separate schools. The initial 1-week baseline phase was followed by a 4-week lottery program in which students arriving in vehicles in which all occupants were properly restrained became eligible to win inexpensive prizes. Baseline use of safety restraints averaged $4 \%$ to $5 \%$ and increased to between $60 \%$ and $70 \%$ during the lottery program. Unfortunately, safety restraint use declined to nearbaseline levels 2 to 3 months following program discontinuance.

It is clear that rewarding parents for their children's use of safety seats produced short-term increases in their use of such devices (Roberts \& Turner, 1986). It is also evident that providing rewards directly to children contingent on safety belt use is likewise temporarily effective in promoting such use. However there exists a clear need to develop and test more effective safety belt use programs targeted toward helping children acquire skills in the use of safety belts and to maintain such behaviors in the absence of contrived reinforcement. We describe the results of one such program.

\section{METHOD}

\section{Subjects}

All children attended the same private elementary school, participated in the after-school child care program, and met the following criteria: (a) they were not involved in any regularly scheduled activities that would preclude their daily attendance at the after-school program, (b) during a 5-day preexperimental observation period they were never observed to use a safety belt when being driven home from school, and (c) their parents completed and returned a permission slip allowing the child to participate in a safety training program and for individual subject data to be recorded. All 16 children meeting these criteria were used in the study. Their ages ranged from 4.8 to 7.1 years $(M=5.1$ years); one child was black and 15 were white; and 12 were male.

\section{Observation Procedure}

Graduate social work student observers (blind to the experimental conditions and hypotheses) were substituted for the usual teachers' aides who walked the children from the classroom or playground to their parents' automobiles at the end of the day. When a parent drove into the loading area they told the "aide" the name of the child he or she wished to pick up. The observer then used a portable radio to call inside the school, requesting that the child be escorted to the street by a second "aide." These two aides (observers) then independently and unobtrusively recorded the child's use or nonuse of a safety belt as they stood next to the departing automobile. To be scored in the affirmative, a lap and shoulder belt had to be correctly fastened before the automobile left the loading area. Portable radios and child escorts had been used by the school for 1 year prior to this study, thus lending themselves well to the observation system.

Observers collected data from 4:00 p.m. to 6:00 p.m. Monday through Friday; safety belt use and nonuse reliabilities were separately calculated, using the formula: $A=$ [agreements/(agreements + disagreements)] $\times 100$. Safety belt use data were collected only for the 16 target children.

\section{Design}

Children were randomly assigned to two groups of eight each, and a multiple baseline across groups design was used to evaluate the efficacy of the behavior change program. Individual data, from which the group percentages of safety belt use were calculated, were collected daily. 


\section{Training Program}

The training program contained four major components, each delivered in a small group setting according to the sequence listed below. All children who attended the after-school program $(N=158)$ received the first three components of this training, but individual data were collected only for the 16 children who met the eligibility criteria listed above, and who participated in the lottery program described below.

Education. The trainer (senior author) presented educational facts about the use of safety belts and discussed with the children famous role models who are known to use safety belts, such as airline and jet fighter pilots, race car drivers, and certain television stars. The children were encouraged to respond by naming additional persons who use safety belts. The trainer presented the use of safety belts as a very grown-up and responsible behavior.

Assertiveness training. The trainer presented several scenarios to the children that involved having them assert themselves regarding safety belt use. The children role-played situations in which they were unable to find the safety belt or were unable to fasten the safety belt before the driver began to drive off. The children practiced requesting assistance from the driver or other passengers and asking that the automobile remain stationary while fastening their safety belts.

Behavioral rebearsal. Children were taken to the school parking lot where three automobiles with different types of safety belts were parked. The children were divided into small groups and practiced getting into the front and back seats of the automobiles and buckling themselves into the available safety belts. This was made into a game, with the children conducting small speed and agility contests among themselves. All children were positively encouraged to practice until they could buckle and unbuckle each form of safety belt within 10 $\mathrm{s}$, and were praised when this was accomplished. Each of the 158 children acquired these skills in $10 \mathrm{~min}$ or less.

Lottery. Each target child in Groups 1 and 2 who was observed to wear his or her safety belt when driven from school became eligible to par- ticipate in the safety belt lottery the following day. Relatively favorable odds were used, with $50 \%$ of the eligible children having their names drawn from a bowl by a teacher who awarded the prizes. The targeted children in Groups 1 and 2 participated in the daily lottery (which was conducted separately from the nontargeted children) until a stable increased level of safety belt use was attained, at which time the eligibility criterion was increased, requiring 2 consecutive days of safety belt use in order to participate. Each group participated in separate lotteries. The prizes consisted of small inexpensive trinkets such as adhesive stickers, toy cars, and coloring books, ranging in value from $24 \uparrow$ to to $59 ₫$ and costing a total of $\$ 78.50$ for the entire program. Other prizes were "Safety Award Certificates," also presented by a teacher, that cost $\$ 6.28$ to construct and duplicate.

\section{RESULTS}

\section{Reliability}

A reliability observer was present during data collection for $91 \%$ of the 34 daily sessions. Interobserver agreements for safety belt use ranged from $80 \%$ to $100 \%$, with a mean of $97.4 \%$. Interobserver agreements for safety belt nonuse ranged from $75.0 \%$ to $100 \%$, with a mean of $96.0 \%$. Due to a shortage of staff, the follow-up data were collected in the absence of a reliability observer.

\section{Safety Belt Use}

Figure 1 depicts the percentage of subjects in each group who were observed to use their safety belts when being driven from school. During the baseline for Group 1, no child was observed to use a safety belt, consistent with their performance during the preexperimental observations. After implementation of the behavioral training program, safety belt use ranged from $62.5 \%$ to $100 \%$, with a mean of $95.5 \%$. For Group 2, baseline safety belt use ranged from $0 \%$ to $40 \%$, with a mean of $6.4 \%$. During the experimental program, safety belt use ranged from $37.5 \%$ to $100 \%$, with a mean of $81.0 \%$. The lottery was discontinued on Day 34 , and follow-up probe observations made during the 


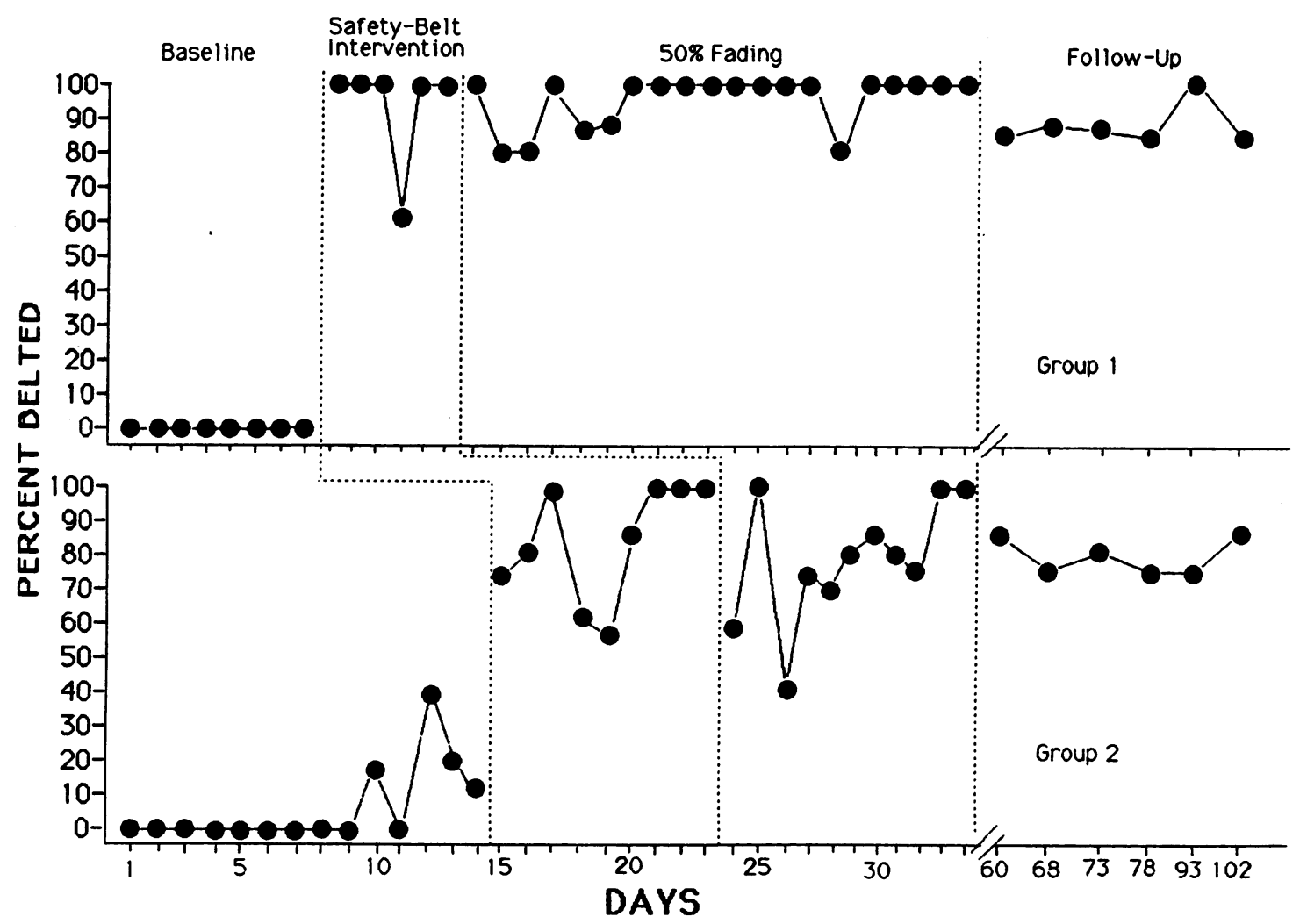

Figure 1. Percentage of safety belt use by eight children in Group 1 and by eight children in Group 2.

following 3 months found safety belt use to range from $86 \%$ to $100 \%$ for Group 1 and from $75 \%$ to $86 \%$ for Group 2. The increase in the baseline belt use for Group 2 was largely due to two siblings who were randomly assigned to the different groups. When the brother in Group 1 received the training and began the lottery, his sister in Group 2 promptly increased her safety belt use, thereby elevating the daily safety use percentage for Group 2's baseline.

\section{Social Validation and Generalization}

To examine the social validity and generalizability of the program, a questionnaire was sent to each child's parents a week after the training began for each group. Of the 16 sets of parents, 15 returned the questionnaire, answering four questions using a 1 (strongly agree) to 5 (strongly disagree) scale $(3=$ neutral). The first question read "My child buckles his or her seat belt when coming to school in the morning." The mean response (and $S D$ ) was 1.7 (1.0), indicating considerable agreement. Question two read "My child buckles his or her seat belt when in the car for travel not related to school activities," and had a mean response of 1.8 $(0.86)$, also indicating general agreement. These two self-report responses suggest that the children were frequently using their safety belts when traveling in an automobile, even though the lottery contingency did not apply to such travel.

The third question, "My child has discussed the use of seat belts with me since receiving training in the safety program," had a mean response of 1.5 (1.1), while the fourth question, "My child appears to have a positive attitude toward the use of seat belts," had a mean response of $1.2(0.41)$. These latter two questions provide further evidence of the favorable impact of the training program.

The intervention program was relatively inexpensive in terms of time and resources. Delivery of 
the intervention package by the first author required approximately 10 hours, including didactic and behavioral training and the conduct of the lotteries. The observations were carried out by graduate social work students without pay (142 hours). The group training of observers (didactic training plus practice observations) required about 4 hours.

\section{DISCUSSION}

Results of this study clearly demonstrate the effectiveness of the training program in promoting safety belt use by young children. The data display immediate and practically significant increases in safety belt use, and these gains were well maintained 2 to 3 months after the program ended. The compliance in safety belt use achieved in this study appears to exceed those obtained in previous studies of either child or adult safety belt use, whose effects were often only temporary.

At the time of this program, Florida did not have a mandatory safety belt use law for either adults or children. Furthermore, all of the children were exempt from Florida's child safety seat law, which only covers children up to 4 years old. Given that we limited our subjects to children who consistently did not use safety belts, our practically significant and well-maintained increases in safety belt use in the absence of laws mandating such use are all the more encouraging.

Future research on child safety belt use could be improved in several ways. Actual observations of safety belt use under noncontingency conditions are necessary to assess the generalizability of safety belt use skills. Our use of parental reports of this measure, while favorable, do not possess the credibility of direct observational measures. The validity of such programs may be further enhanced by assessing the program's impact on the safety belt use of other family members, as was done by Roberts and Fanurik (1986), and by a more systematic appraisal of parental endorsement of the value of such programs. Future studies should also incorporate longer follow-up periods.

Our study adds to the growing body of research on promoting the acquisition of independent health and safety skills by young children. Other areas of similar research include the teaching of self-protection skills against abduction (Poche, Brouwer, \& Swearingen, 1981), dental hygiene skills (Swain, Allard, \& Holborn, 1982), pedestrian skills (Yeaton \& Bailey, 1978), and emergency fire safety skills (Jones, Kazdin, \& Haney, 1981). Given the relatively high probability (more than $50 \%$ ) that young children will be involved in an automobile accident during their lifetime (Kahn, 1973), the social significance of this and related research on safety belt promotion is obvious.

\section{REFERENCES}

Geller, E. S., Bruff, C. D., \& Nimmer, J. G. (1985). “Flash for Life": Community-based prompting for safety belt promotion. Journal of Applied Bebavior Analysis, 18, 309-314.

Geller, E. S., Casali, J., \& Johnson, R. (1980). Seat belt usage: A potential target for applied behavior analysis. Journal of Applied Bebavior Analysis, 13, 669-675.

Highway Safety Research Center. (1976). Belts-Questions and answers. Highway Safety Highlights, 10, 1.

Jones, R. T., Kazdin, A. E., \& Haney, J. I. (1981). Social validation and training of emergency fire safety skills for potential injury prevention and life saving. Journal of Applied Behavior Analysis, 14, 249-260.

Kahn, J. (1973). Who wants safer cars? World Magazine, 3, pp. 25, 28, 59.

National Safety Council. (1983). Accident facts. Chicago, IL: Author.

Poche, C., Brouwer, R., \& Swearingen, M. (1981). Teaching self-protection to young children. Journal of Applied Bebavior Analysis, 14, 169-176.

Roberts, M. C., \& Fanurik, D. (1986). Rewarding elementary schoolchildren for their use of safety belts. Health Psychology, 5, 185-196.

Roberts, M. C., \& Turner, D. S. (1984). Preventing death and injury in childhood: A synthesis of child safety seat efforts. Health Education Quarterly, 11, 181-193.

Roberts, M. C., \& Turner, D. S. (1986). Rewarding parents for their children's use of safety seats. Journal of Pediatric Psychology, 11, 25-36.

Sowers-Hoag, K. M. (1986). Promoting safety belt use among young children: An experimental analysis. Unpublished Doctoral dissertation, Florida State University, Tallahassee.

Streff, F. M., \& Geller, E. S. (1986). Strategies for motivating safety belt use: The application of applied behavior analysis. Health Education Research, 1, 47-59.

Swain, J. J., Allard, G. B., \& Holborn, S. W. (1982). The good toothbrushing game: A school-based dental hygiene program for increasing the toothbrushing effectiveness of children. Journal of Applied Behavior Analysis, 15, 171-176. 
Thyer, B. A., \& Geller, E. S. (in press). The "buckle-up" dashboard sticker: An effective environmental intervention for safety belt promotion. Environment and $\mathrm{Be}$ havior.

Thyer, B. A., Geller, E. S., Williams, M., \& Purcell, E. (in press). Community-based "flashing" to increase safety belt use. Journal of Experimental Education.

Yeaton, W. S., \& Bailey, J. S. (1978). Teaching pedestrian safety skills to young children: An analysis and one-year followup. Journal of Applied Behavior Analysis, 11, 315-329.

Received July 7, 1986

Initial editorial decision August 20, 1986

Revisions received November 6, 1986; December 4, 1986

Final acceptance December 19, 1986

Action Editor, E. Scott Geller 